\title{
Harmol induces autophagy and subsequent apoptosis in U251MG human glioma cells through the downregulation of survivin
}

\author{
AKIHISA $\mathrm{ABE}^{1}$ and HIROKO KOKUBA ${ }^{2}$ \\ ${ }^{1}$ Department of Biochemistry and ${ }^{2}$ Laboratory of Electron Microscopy, \\ Tokyo Medical University, Shinjuku-ku, Tokyo 160-8402, Japan
}

Received October 10, 2012; Accepted November 12, 2012

DOI: $10.3892 /$ or.2013.2242

\begin{abstract}
The $\beta$-carboline alkaloids are plant substances that exhibit a wide spectrum of neuropharmacological, psychopharmacological and antitumor effects. In the present study, we found that harmol, a $\beta$-carboline alkaloid, induced autophagy and suppression of survivin expression, and subsequently induced apoptotic cell death in U251MG human glioma cells. Autophagy was induced within $12 \mathrm{~h}$ by treatment with harmol. When treated for over $36 \mathrm{~h}$, however, apoptotic cell death was induced. Harmol treatment also reduced survivin protein expression. Small interfering RNA (siRNA)-mediated knockdown of survivin enhanced the harmol-induced apoptosis. Knockdown of survivin by siRNA also induced autophagy. Therefore, harmol-induced apoptosis is a result of the reduction in survivin protein expression. Treatment with 3-methyladenine (3-MA) in the presence of harmol did not affect the expression of survivin and diminished harmol-induced cell death. Treatment with chloroquine in the presence of harmol did not suppress the reduction of survivin expression and increased harmol-induced cell death. From these results, harmol-induced reduction of survivin expression was closely related to autophagy. It is assumed that when isolation membrane formation is inhibited by treatment with 3-MA, reduction of survivin protein expression and apoptotic cell death were not induced. However, when isolation membrane formation is started and an autophagosome is formed, survivin expression is suppressed and apoptosis is executed. Harmol treatment reduced phosphorylation of Akt, mammalian target of rapamycin (mTOR) and its downstream targets p70-ribosomal protein S6 kinase and 4E-binding protein 1 , resulting in induction of autophagy. Conversely, activation of the Akt/mTOR pathway inhibited harmol-induced autophagy and cell death. These findings indicate that harmol-induced autophagy involves the Akt/mTOR pathway. Taken together,
\end{abstract}

Correspondence to: Dr Akihisa Abe, Department of Biochemistry, Tokyo Medical University, 6-1-1 Shinjuku, Shinjuku-ku, Tokyo 160-8402, Japan

E-mail: aabe-bc@tokyo-med.ac.jp

Key words: harmol, autophagy, apoptosis, survivin, mammalian target of rapamycin pathway autophagy induced by harmol represented a pro-apoptotic mechanism, and harmol suppressed the expression of survivin and subsequently induced apoptosis.

\section{Introduction}

Gliomas are the most common type of malignant brain tumors and are resistant to many types of treatments, including chemotherapy, radiation and other adjuvant therapies. Patients with the most malignant histopathologic subtype, glioblastoma, present with the worst prognosis, with a median survival length of less than one year, despite aggressive surgery with adjuvant radiotherapy and chemotherapy $(1,2)$. In addition, glioma cells are prone to acquire drug resistance (3). Currently, there is still a need to identify chemotherapeutic agents with cytotoxic effects exclusively targeted against malignant glioma cells. Improved chemotherapeutic regimens and other strategies are urgently needed.

'Apoptosis', signifying genetically controlled programmed cell death (PCD), not only plays a crucial role during tissue development and homeostasis, but is also involved in a wide range of pathologies (4). Since the 1960s, various morphological forms of PCD have been recognized. Clarke classified cell death into 4 types, including type I PCD (apoptosis) and type II PCD (autophagy) (5). Evasion of apoptosis is a hallmark of most malignant cells and contributes to the insensitivity to various current cancer therapies (6). Numerous studies have demonstrated that most chemotherapeutic agents and certain naturally occurring compounds induce cell death by activating the apoptotic pathways. It is thought that apoptosis induction in tumor cells, with either drugs or natural products, is an effective therapy for cancer and immune system diseases.

Autophagy is one of the major regulatory mechanisms in the degradation of intracellular proteins and organelles $(7,8)$. It is a highly conserved evolutionary process which occurs in the cells of all eukaryotic organisms, from yeasts to humans. During autophagy, the cytosol and entire organelles become encased in double-membrane-bound vacuoles (autophagosomes), and subsequently fuse with lysosomes to form autolysosomes and are eventually degraded by lysosomal hydrolases (7). Although originally characterized as a survival response to nutrient deficiency, autophagy is now recognized as being frequently induced in response to a variety of stressors to maintain cellular homeostasis (9-11). The importance of 
autophagy has been emphasized in various biological fields, including cancer (10,12-14). Furthermore, cancer cells undergo less autophagy than normal cells $(15,16)$. These findings indicate that autophagy induction is an attractive modality of anticancer therapy.

$\beta$-carboline alkaloids are present in several medicinal plants, including Peganum harmala, Passiflora incarnate, and Bansteriopsis caapi $(17,18)$. These plants have been used in traditional medicine to treat asthma, jaundice, lumbago, and other human ailments (18-20). The $\beta$-carboline alkaloids are also found in common plants (e.g., wheat, rice, soybeans, grapes) and plant-derived drinks (e.g., wine, beer, whisky, brandy) (21). It is known that they also exist in mammalian tissues $(22,23)$. It has been reported that certain $\beta$-carboline alkaloids and their related compounds exhibit cytotoxic effects on cancer cells (24-26). We also previously reported that harmol, a $\beta$-carboline alkaloid, induced apoptosis (27) and autophagic cell death in human non-small cell lung cancer cells (28).

In the present study, we investigated the anticancer effect of harmol on the U251MG human glioma cell line. Furthermore, we examined the types of cell death which were induced by harmol and the possible mechanisms.

\section{Materials and methods}

Chemicals. Harmol (purity, minimum 98\%) (Fig. 1), dimethyl sulfoxide (DMSO), 3-methyladenine (3-MA) and chloroquine (CQ) were purchased from Wako Pure Chemical Industries, Ltd. (Osaka, Japan). Harmol was dissolved in DMSO at a concentration of $200 \mathrm{mM}$, and stored at $-20^{\circ} \mathrm{C}$ until use. Monodansylcadaverine (MDC) was obtained from Sigma-Aldrich (St. Louis, MO, USA). Caspase substrates Ac-DEVD-7-amino-4-trifluoromethyl coumarin (AFC) (caspase-3), Ac-IETD-AFC (caspase-8), and Ac-LEHD-AFC (caspase-9) were obtained from MBL (Nagoya, Japan). A recombinant full-length human active Akt1 protein (rAkt1) was purchased from R\&D Systems, Inc. (Minneapolis, MN, USA).

Cell lines and culture conditions. Human glioma cell line U251MG was obtained from the Human Science Research Resources Bank (Osaka, Japan). This cell line was cultured in Dulbecco's modified Eagle's medium (Wako) with $80 \mathrm{mg} / \mathrm{l}$ kanamycin sulfate (Wako) and heat-inactivated fetal bovine serum (Biowest, Miami, FL, USA) and maintained at $37^{\circ} \mathrm{C}$ in an incubator containing $95 \%$ air and $5 \% \mathrm{CO}_{2}$.

Cell viability. Cell viability was assessed with the CellTiterBlue cell viability assay kit (Promega Corp., Madison, WI, USA). In viable cells, resazurin, which is contained in the CellTiter-Blue cell viability assay reagent, is metabolized to the fluorescent product resorufin. The tumor cells $\left(4.5 \times 10^{4}\right.$ cells/ well) were precultured in a 48 -well flat-bottom microtiter plate overnight at $37^{\circ} \mathrm{C}$ in a $5 \% \mathrm{CO}_{2}$ humidified chamber. Then, various concentrations of harmol were added and the cells were incubated for 24-48 h. After incubation, $100 \mu \mathrm{l}$ of CellTiter-Blue assay reagent (Promega Corp) was added to each well and the cells were further incubated for $1.5 \mathrm{~h}$. After incubation, the medium of each well was analyzed using a Powerscan HT microplate reader (DS Pharma Biomedical Co.,

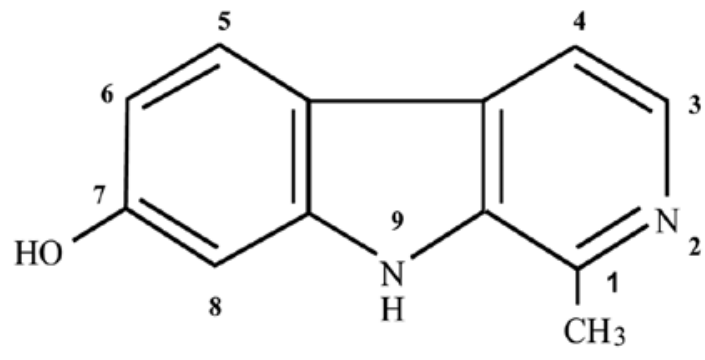

Figure 1. Chemical structure of harmol.

Osaka, Japan) at an excitation wavelength of $560 \mathrm{~nm}$ and an emission wavelength of $590 \mathrm{~nm}$. Cell viability was determined based on the fluorescence intensity of non-treated cells.

Assay for caspase activity. Caspase activity was measured using fluorogenic peptide substrates. Both untreated control cells and cells which had been treated with $75 \mu \mathrm{M}$ harmol were washed with ice-cold phosphate-buffered saline (PBS) and suspended in lysis buffer [100 mM HEPES (pH 7.5), $150 \mathrm{mM}$ $\mathrm{NaCl}, 1 \%$ Nonidet P-40, $1 \mathrm{mM}$ EDTA, $1 \mathrm{mM}$ dithiothreitol (DTT), $1 \mathrm{mM}$ phenylmethylsulfonyl fluoride, $10 \mu \mathrm{M}$ leupeptin and $1 \mu \mathrm{M}$ pepstatin] for $20 \mathrm{~min}$ on ice, followed by centrifugation at $12000 \mathrm{x} \mathrm{g}$ for $10 \mathrm{~min}$ at $4^{\circ} \mathrm{C}$. In total, $50-70 \mu \mathrm{g}$ of protein in $40 \mu \mathrm{l}$ of buffer solution was mixed with $10 \mu \mathrm{l}$ of $5 \mathrm{mM}$ fluorogenic report substrate, for each individual caspase: Ac-DEVD-AFC for caspase-3, Ac-IETD-AFC for caspase-8 and Ac-LEHD-AFC for caspase-9. The reaction mixture was added to $50 \mu 1$ of assay buffer [20 mM HEPES (pH 7.4), $0.1 \mathrm{M}$ $\mathrm{NaCl}, 5 \mathrm{mM}$ DTT, $0.1 \%$ Nonidet P-40], and incubated at $37^{\circ} \mathrm{C}$ for $1 \mathrm{~h}$. The enzymatic product, AFC, which was released from the substrate, was excited at $400 \mathrm{~nm}$ to measure its emission at $505 \mathrm{~nm}$. Untreated cells were used as a control.

Visualization of MDC-labeled vacuoles in harmol-treated A549 cells. U251MG cells were treated with $100 \mu \mathrm{M}$ harmol for $0-12 \mathrm{~h}$ at $37^{\circ} \mathrm{C}$, and then further treated with $30 \mu \mathrm{M}$ MDC for $10 \mathrm{~min}$. After treatment, cells were washed 3 times with PBS and immediately observed by fluorescence microscopy (BZ-8100, Keyence Co., Osaka, Japan).

Electron microscopy. Cultured U251MG cells with and without $100 \mu \mathrm{M}$ harmol treatment were rinsed with phosphate buffer (PB) (0.1 M, pH 7.4). Cells were then fixed with $2.5 \%$ glutaraldehyde in PB for $3 \mathrm{~h}$ at $4^{\circ} \mathrm{C}$, rinsed with PBS for $5 \mathrm{~min}$ at least 3 times, and post-fixed with $1 \%$ osmium tetroxide for $1 \mathrm{~h}$ at $4^{\circ} \mathrm{C}$, followed by dehydration in a graded ethanol series for $5 \mathrm{~min}$ at room temperature (RT). After dehydration with absolute ethanol, cells were treated with a mixture of absolute ethanol and Spurr resin $(1: 1, v / v)$ for $1 \mathrm{~h}$ at RT. Then, the mixture was replaced with pure Spurr resin and cells were treated for $1 \mathrm{~h}$ at RT, twice. The pellets were transferred to a BEEM capsule, overlaid with new resin and subjected to resin polymerization at $70^{\circ} \mathrm{C}$ for $16 \mathrm{~h}$. Ultrathin sections were cut with an Ultracut E microtome (Reichert-Jung Co., Vienna, Austria), stained with uranyl acetate and lead citrate, and examined using a JEM-1230 transmission electron microscope (JEOL, Tokyo, Japan). 


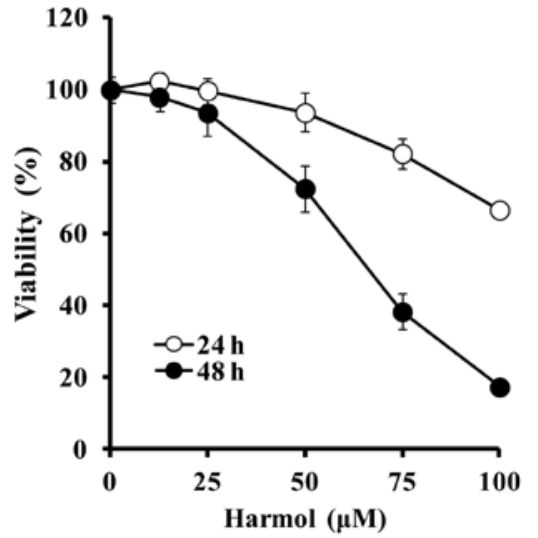

Figure 2. Effects of harmol treatment on U251MG human glioma cells U251MG cells were treated with various concentrations of harmol for 24-48 h. Control cells were treated with the same volume of DMSO vehicle alone (the final concentration of DMSO was $<0.1 \%$ ). After treatment, cell viability was measured by the CellTiter-Blue assay reagent as described in Materials and methods, and then calculated as a percentage of viability of the control cells. The results of harmol treatment assays are presented as means $\pm \mathrm{SD}$, based on 3 independent experiments.

Western blot analysis. Whole cell proteins were isolated from untreated and harmol-treated U251MG cells. After treatment, the cells were centrifuged at $300 \mathrm{x}$ g for $5 \mathrm{~min}$, and the pellet was lysed in a buffer containing $25 \mathrm{mM}$ HEPES ( $\mathrm{pH} 7.4$ ), $150 \mathrm{mM} \mathrm{NaCl}, 0.5 \%$ Triton X-100, 10\% glycerol, $1 \mathrm{mM}$ DTT, $1 \mathrm{mM}$ sodium orthovanadate, $25 \mathrm{mM} \beta$-glycerophosphate, $1 \mathrm{mM} \mathrm{NaF}$ and $5 \mu \mathrm{l} / \mathrm{ml}$ protease inhibitor cocktail (Wako). The protein content of each lysate was determined using a BCA protein assay kit (Pierce Biotechnology Inc., Rockford, IL, USA). Protein lysates were then mixed with an equal volume of gel loading buffer [20\% glycerol, $4 \%$ sodium dodecyl sulfate (SDS), $100 \mathrm{mM}$ Tris, $5 \% \beta$-mercaptoethanol and $0.01 \%$ bromophenol blue] before being boiled for $5 \mathrm{~min}$. After boiling, $40 \mu \mathrm{g}$ of protein was subjected to SDS-polyacrylamide gel electrophoresis. Proteins were then transferred onto a polyvinylidene fluoride membrane (PVDF; GE Healthcare UK Ltd., Buckinghamshire, UK). Blots were then blocked for $1 \mathrm{~h}$ at RT in 5\% non-fat dry milk diluted in Tris-buffered saline supplemented with 0.1\% Tween-20 (TBS-T) (ICN Biomedicals Inc., Aurora, OH, USA). The following primary antibodies were incubated overnight at RT in TBS-T as follows: rabbit anti-poly(ADP-ribose)-polymerase (PARP) (Cell Signaling Technology Inc., Danvers, MA, USA; 1:1000), rabbit anti-Akt (Cell Signaling Technology; 1:1000), rabbit anti-phospho-Akt (p-Akt) (Cell Signaling Technology; 1:1000), rabbit anti-mammalian target of rapamycin (mTOR) (Cell Signaling Technology; 1:1000), rabbit anti-phospho-mTOR (p-mTOR) (Cell Signaling Technology; 1:1000), rabbit anti-70 kDa ribosomal protein S6 kinase (P70S6K) (Cell Signaling Technology; 1:1000), rabbit anti-phospho-P70S6K (p-P70S6K) (Cell Signaling Technology; 1:1000), rabbit anti-eukaryotic translation initiation factor 4E-binding protein 1 (4E-BP1) (Cell Signaling Technology; 1:1000), rabbit anti-phospho-4E-BP1 (p-4E-BP1) (Cell Signaling Technology; 1:1000), mouse anti-microtubuleassociated protein 1 light chain 3 (LC3) (MBL; 1:1000), and mouse anti- $\beta$-actin (Sigma-Aldrich; $1: 3000)$. Peroxidaseconjugated secondary antibodies were incubated for $1 \mathrm{~h}$ at
RT as follows: goat anti-mouse IgG (Jackson Immunoresearch Laboratories Inc., West Grove, PA, USA; 1:5000) or goat antirabbit IgG (Cell Signaling Technology; 1:2000). Blots were then washed with TBS-T and developed using Immobilon chemiluminescent substrate (Millipore Corp., Billerica, MA, USA).

Survivin siRNA transfection. Knockdown of survivin expression in U251MG cells was achieved by transfection of siRNA. The control and survivin siRNAs (Cell Signaling Technology) were diluted to a final concentration of $20 \mathrm{nM}$ in Opti-Mem I (Invitrogen Corp., Carlsbad, CA, USA), and transfection was performed with cells at $40-50 \%$ confluency using Lipofectamine 2000 transfection reagent (Invitrogen) according to the manufacturer's protocol.

Statistical analysis. Results are presented as means \pm SD. Statistical comparisons of the results were carried out using analysis of variance. A P-value of $<0.05$ was considered to indicate a statistically significant difference. Differences between the means of control and treated cells were analyzed by Dunnett's test.

\section{Results}

Cytotoxic effects of harmol on U251MG cells. Continuous treatment of U251MG human glioma cells with harmol for 24 and $48 \mathrm{~h}$ induced growth inhibition and cell death in a timeand dose-dependent manner (Fig. 2). The cell viabilities of $\mathrm{U} 251 \mathrm{MG}$ cells exposed to harmol at various concentrations of $12.5,25,50,75$, and $100 \mu \mathrm{M}$ in triplicate for $24 \mathrm{~h}$ were 102.3 , $99.8,93.7,82.3$, and $66.7 \%$, respectively. After treatment with harmol for $48 \mathrm{~h}$, the cell viabilities decreased to 98.0, 93.6, $72.5,38.2$, and $17.3 \%$, respectively (Fig. 2).

Changes in caspase activities and poly-(ADP-ribose)polymerase (PARP) cleavage. To confirm whether the cell death induced by harmol treatment was due to apoptosis, the activities of 3 types of caspases were examined (Fig. 3A). Harmol showed no noticeable effect on the activities of these caspases within the 24-h treatment. However, in the 36-h treatment, activities of caspase- 3 and -9 were elevated to 486 and $346 \%$, respectively, while caspase- 8 activity showed no significant change. We also examined the effects of harmol on PARP cleavage. PARP is a key participant in DNA base excision repair and in maintaining genome integrity. PARP is well known as an endogenous substrate for caspase-3 and an early marker of apoptosis (29). After treatment with harmol for $6-48 \mathrm{~h}$, the cleaved form of PARP ( $89 \mathrm{kDa})$ was detected at 36 and $48 \mathrm{~h}$ following treatment of the cell lysate (Fig. 3B). These data indicated that treatment with harmol for over $36 \mathrm{~h}$ induced apoptosis in U251MG cells.

Harmol treatment suppresses survivin protein expression. While harmol was shown to induce apoptosis in U251MG cells, the mechanisms of inducing this phenomenon were unclear. Afterwards, we investigated the effect of harmol treatment on the expression of survivin protein, which is a known anti-apoptotic protein. From the results, harmol treatment was shown to suppress the expression of survivin protein in a doseand time-dependent manner (Fig. 4). 
A

$$
\text { हैं }
$$

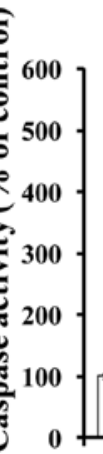

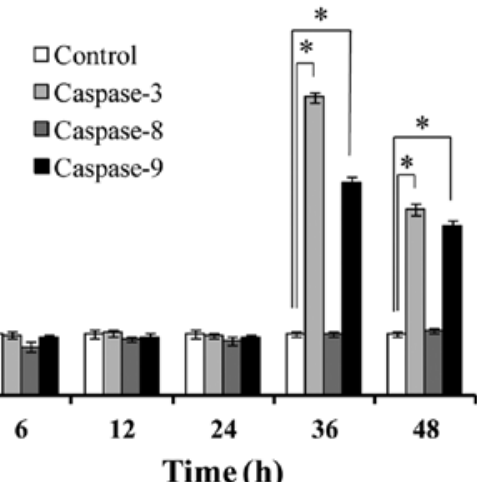

B

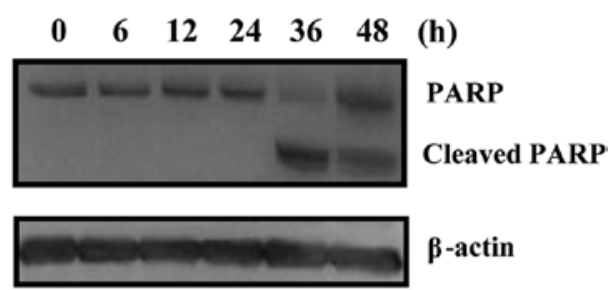

Figure 3. Effects of harmol treatment on caspase activity and cleavage of PARP in U251MG cells. (A) The activities of caspase-3, -8 , and -9 in U251MG cells were measured as described in Materials and methods. Each value is expressed as mean \pm SD, based on 3 independent experiments. "Significant difference between non-treated control and harmol-treated cells $(\mathrm{P}<0.001)$. (B) After treatment with $100 \mu \mathrm{M}$ harmol for the indicated times, PARP cleavage was examined by western blot analysis.

A

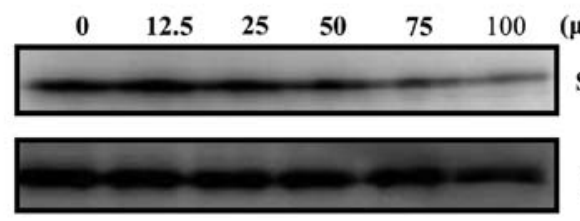

B

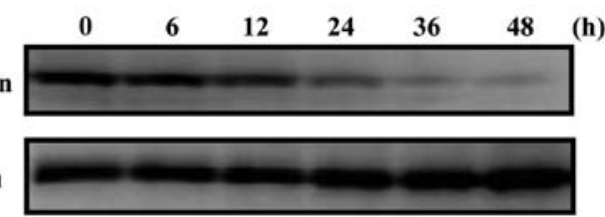

Figure 4. Harmol treatment decreases survivin protein expression. (A) U251MG cells were treated with different concentrations of harmol for $24 \mathrm{~h}$ and subjected to western blot analysis. (B) Time course effect of harmol on survivin protein expression. U251MG cells were treated with $100 \mu \mathrm{M}$ harmol for the indicated times. The amount of protein loaded in each lane was assessed by stripping and reprobing with a $\beta$-actin antibody.

Non-labeled cells
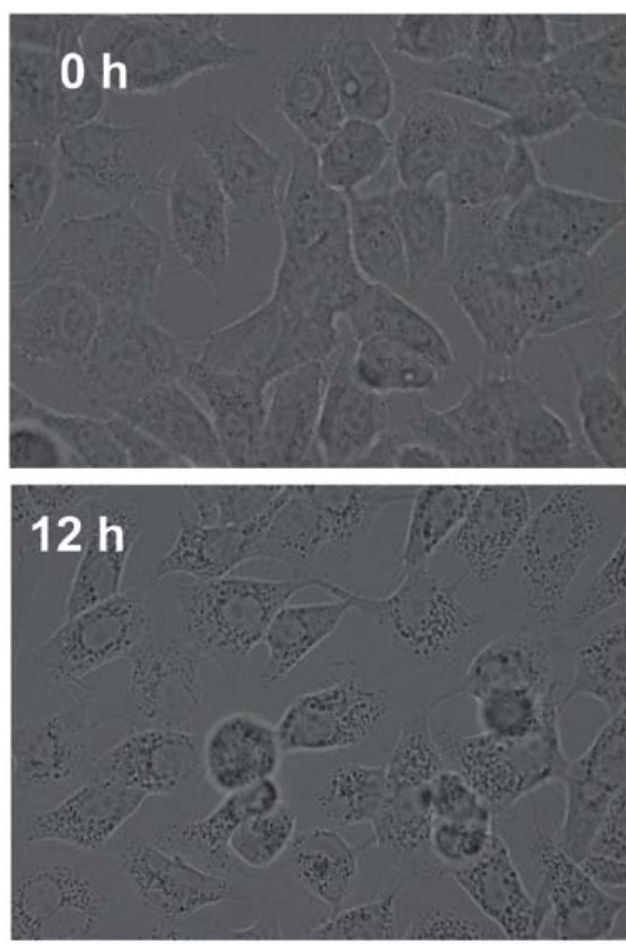

MDC-labeled cells
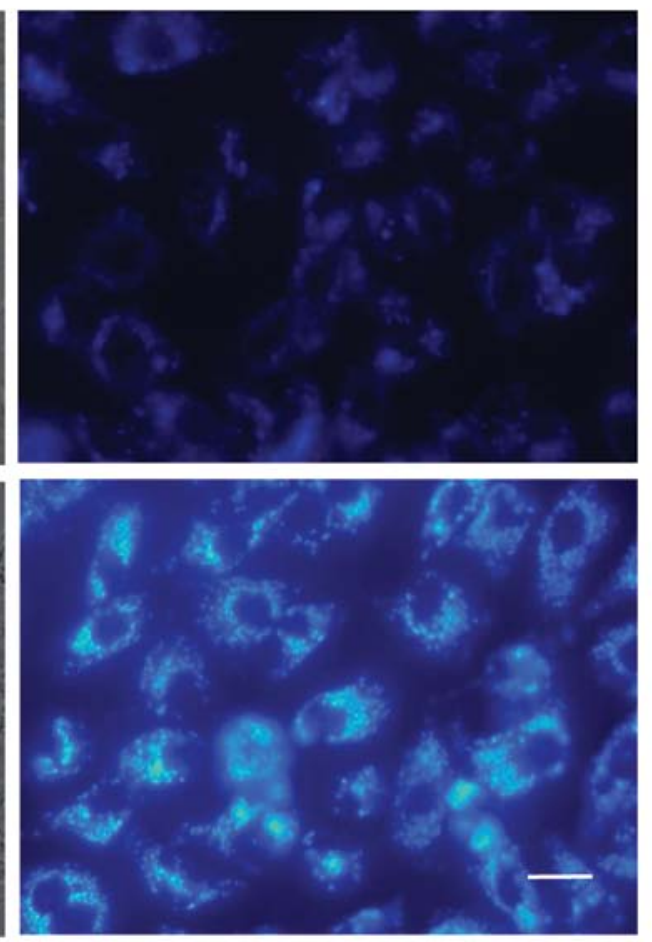

Figure 5. Harmol-induced vacuolization and formation of MDC-labeled vesicles in U251MG cells. (Left panels) U251MG cells were treated or not treated with $100 \mu \mathrm{M}$ harmol for $0-12 \mathrm{~h}$ before phase contrast microscopic observation. (Right panels) After treatment with $100 \mu \mathrm{M}$ harmol for the indicated times, the cells were further incubated with $25 \mu \mathrm{M}$ MDC for $10 \mathrm{~min}$. Then, the cells were washed twice with PBS and immediately analyzed by fluorescence microscopy (scale bar, $20 \mu \mathrm{m}$ ). 
Non-treated cell

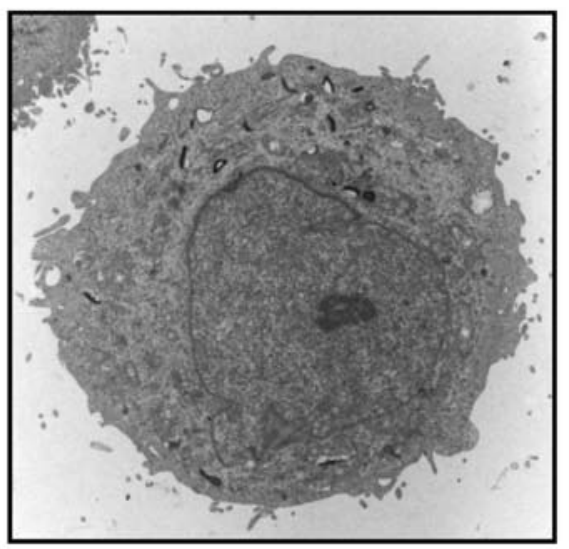

Harmol-treated cell

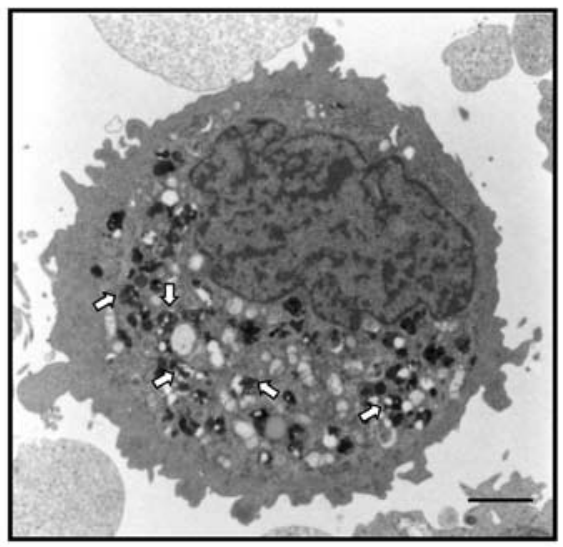

Figure 6. Electron micrographs of harmol-treated U251MG cells. Non-treated control cells (left panel). U251MG cells were treated with $100 \mu \mathrm{M}$ harmol for $12 \mathrm{~h}$ (right panel). The white arrows point to autophagic vacuoles and autolysosomes (scale bar, $2 \mu \mathrm{m}$ ).

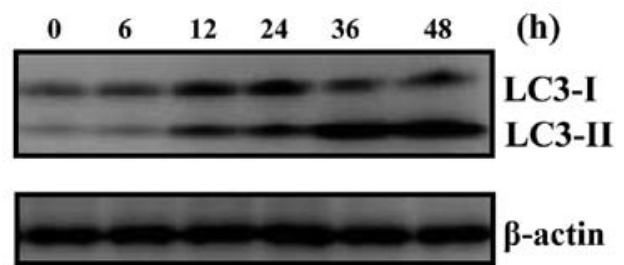

Figure 7. Chronological course of autophagy induction by harmol. U251MG cells were treated with $100 \mu \mathrm{M}$ harmol for the indicated times. Autophagy induction was evaluated by the detection of LC3-II protein accumulation. The levels of LC3-I and LC3-II proteins were determined by western blot analysis with anti-LC3 antibody. The amount of protein loaded in each lane was assessed by stripping and reprobing with a $\beta$-actin antibody.

Formation of autophagic vacuoles following treatment with harmol. Phase contrast microscopy of harmol-treated U251MG cells showed numerous, high-density vacuoles (Fig. 5, left lower panel). Based on the above findings, we would have expected these vacuoles to be formed upon harmol treatment; they were not detected in untreated cell autophagosomes. The fluorescent compound MDC is a specific marker for autophagosomes (30), and is commonly used to stain autophagic vesicles. We studied the incorporation of MDC in cells where autophagy was stimulated by harmol treatment. U251MG cells were treated with $100 \mu \mathrm{M}$ harmol for $12 \mathrm{~h}$ and then analyzed by fluorescence microscopy. As shown in Fig. 5 (right upper panel), in control cells ( 0 h treatment), MDC-labeled vacuoles were scarcely detected. On the other hand, in cells which were treated with harmol for $12 \mathrm{~h}$, numerous MDC-labeled fluorescent dots were clearly detected (Fig. 5, right lower panel). Although MDC-labeled fluorescent dots were observed in harmol-treated U251MG cells, in order to identify them more precisely, we performed electron microscopy to obtain ultrastructural information regarding the morphology of harmol-induced autophagy in U251MG cells. Fig. 6 shows an electron micrograph of a non-treated U251MG cell (left panel) and a U251MG cell treated with harmol (right panel). Although the electron micrograph of the harmol-treated U251MG cell showed numerous cytoplasmic phagolysosomes that contained highly electron-dense materials (Fig. 6, right panel), few phagolysosomes were observed in the control cell (Fig. 6, left panel).

Quantitative detection of microtubule-associated protein 1 light chain 3 (LC3). To quantify the incidence of harmolinduced autophagy, we examined the expression of LC3-I and LC3-II proteins using western blot analysis, as these proteins are essential to the formation of autophagosomes (especially LC3-II) and have been widely used for estimating the number of autophagosomes or the incidence of autophagy (31). The expression of LC3-II protein in harmol-treated cells was detected within $12 \mathrm{~h}$, and increased during treatment in a timedependent manner (Fig. 7). Taken together, these results also indicated that harmol induced autophagy, and that harmolinduced autophagy preceded apoptosis in U251MG cells (Fig. 3 vs. Figs. 5-7)

Role of autophagy in harmol-mediated cell death. Autophagy plays an important role in the regulation of cell survival or death $(7,8)$. To determine whether the induction of autophagy by harmol is related to survival or death mechanisms, we investigated the effect of harmol on cell survival in the presence of autophagy inhibitors in U251MG cells. As shown in Fig. 8A, 3-MA, a specific inhibitor of the early stage autophagic process (32), reduced the harmol-induced cell death in U251MG cells. On the other hand, the late stage autophagy inhibitor CQ (33) increased the harmol-induced cell death. On western blot analysis, although treatment with harmol alone induced the expression of LC3-II protein (known as an autophagy marker), co-treatment with harmol and 3-MA notably suppressed LC3-II protein expression (Fig. 8B). In contrast, co-treatment with harmol and CQ induced progressive accumulation of LC3-II throughout the $24 \mathrm{~h}$ duration assay (Fig. 8B). Following treatment with harmol alone for $24 \mathrm{~h}$, although PARP cleavage was not induced (Figs. 3 and 8B), CQ treatment in the presence of harmol induced PARP cleavage. Regarding the anti-apoptotic protein survivin, although $>24 \mathrm{~h}$ of treatment with $100 \mu \mathrm{M}$ harmol strongly suppressed the expression of survivin protein (Fig. 6), the combination treatment of harmol with 3-MA did not suppress the expression of survivin protein (Fig. 8B). However, co-treatment with harmol 

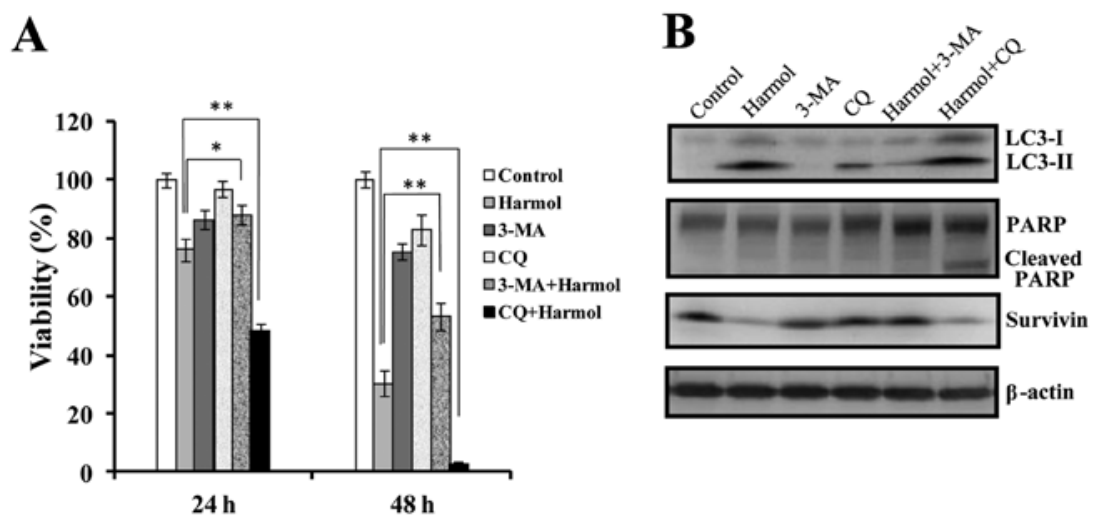

Figure 8. Effects of autophagy inhibitors on harmol treatment-induced cell death. (A) U251MG cells were pretreated with $3 \mathrm{mM} 3-\mathrm{MA}$ or $25 \mu \mathrm{M} \mathrm{CQ}$ for $1 \mathrm{~h}$ before the addition of $100 \mu \mathrm{M}$ harmol, and for an additional incubation of 24-48 h. Viability was assessed as described in Materials and methods. The data shown are the means from 3 independent experiments. Each value is expressed as mean $\pm \mathrm{SD}$. ${ }^{* *} \mathrm{P}<0.001$, ${ }^{*} \mathrm{P}<0.05$. (B) Western blot analysis of LC3, PARP, and survivin. U251MG cells were treated with harmol alone, $3 \mathrm{mM} 3-\mathrm{MA}$ alone, $25 \mu \mathrm{M}$ CQ alone, or their combinations, for $24 \mathrm{~h}$. After treatment, samples were lysed and subjected to western blot analysis. The amount of protein loaded in each lane was assessed by stripping and reprobing with a $\beta$-actin antibody.

A

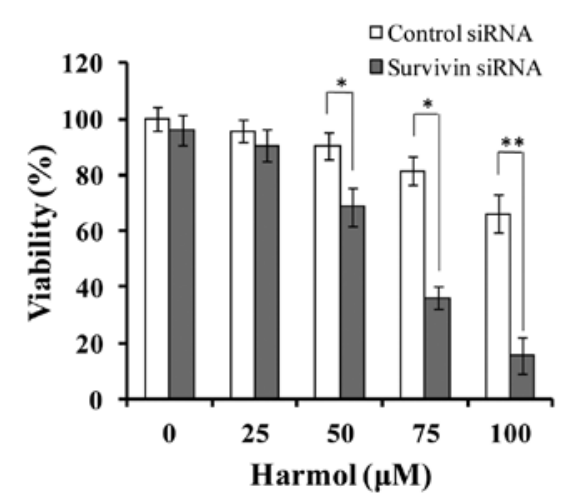

B

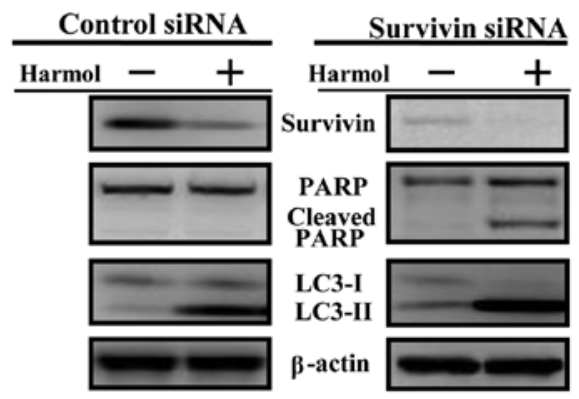

Figure 9. Effects of siRNA survivin knockdown on harmol-induced cytotoxicity. (A) U251MG cells were pretreated with either siRNA for survivin or control scramble siRNA for $36 \mathrm{~h}$ and subsequently treated with various concentrations of harmol for $24 \mathrm{~h}$. After treatment, viability was assessed by the CellTiter-Blue assay reagent as described in Materials and methods. (B) U251MG cells were pretreated as in A and then with $100 \mu \mathrm{M}$ harmol for an additional $24 \mathrm{~h}$. After treatment, cells were subjected to western blotting for detection of survivin, PARP and LC3. The data shown are the means from 3 independent experiments. Each value is expressed as mean \pm SD. ${ }^{*} \mathrm{P}<0.001$ and ${ }^{* *} \mathrm{P}<0.0001$ indicate a significant difference between harmol-treated control siRNA cells and harmoltreated survivin siRNA cells.

and CQ did not suppress the reduction of survivin protein expression in U251MG cells (Fig. 8B).

Genetic suppression of survivin protein expression increases harmol-induced apoptosis. To demonstrate whether harmolinduced apoptosis is related to the suppression of survivin protein expression, we performed siRNA-mediated knockdown of survivin in U251MG cells. As a result, although in control-siRNA transfected U251MG cells, PARP cleavage was not detected within the $24 \mathrm{~h}$ treatment of harmol, in cells where the expression of survivin protein was supressed by transfection with survivin siRNA, PARP cleavage was detected within $24 \mathrm{~h}$ following treatment with harmol (Fig. 9B). In addition, siRNA depletion of survivin protein induced autophagy, which was confirmed by LC3-II protein expression (Fig. 9B, the non-treated control of the survivin-siRNA transfected cell sample was compared with the non-treated control of the control-siRNA transfected cell sample). Furthermore, in the cytotoxicity experiment, the suppression of survivin expres- sion by siRNA increased the harmol-induced cytotoxicity (Fig. 9A).

Akt/mTOR signaling pathway is involved in harmol-induced autophagy in U251MG cells. Our next objective was to identify and characterize the molecular pathways involved in harmolinduced autophagy. The classical pathway that regulates autophagy involves the serine/threonine kinase, mTOR (34). The Akt/mTOR/P70S6K, 4E-BP1 pathway is the main regulatory pathway that negatively regulates autophagy. However, several pathways appear to regulate autophagy in mammalian cells. Thus, we investigated whether the autophagy induced by harmol is mediated by an mTOR-dependent or -independent pathway using western blot analysis (Fig. 10). Harmol treatment caused a significant time-dependent decrease in the phosphorylation of Akt protein in U251MG cells. Equally, harmol treatment diminished the levels of the phosphorylated (activated) form of mTOR, a downstream target of Akt which may inhibit cell growth and induce autophagy. Furthermore, 

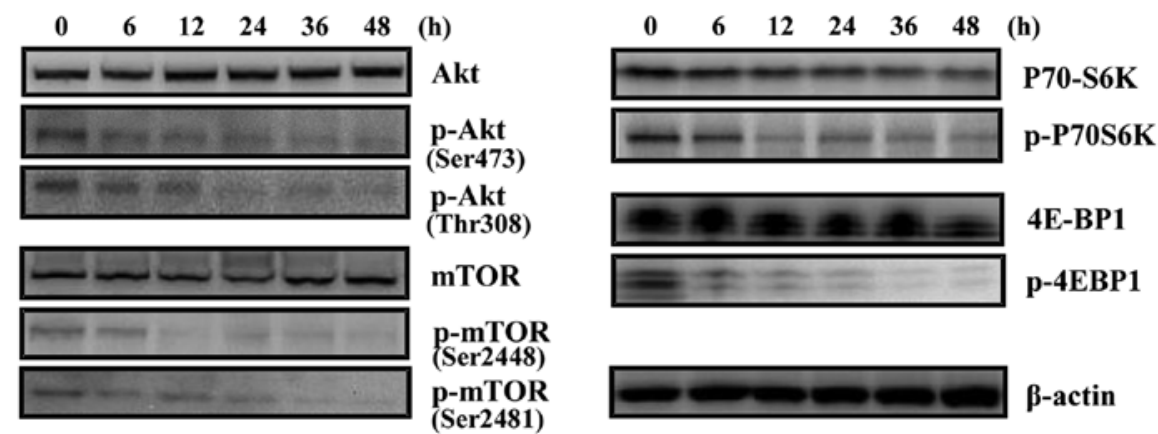

Figure 10. Harmol treatment affects the Akt/mTOR pathway in U251MG cells. U251MG cells were treated with $100 \mu \mathrm{M}$ harmol for the indicated times, and then subjected to western blot analysis. The amount of protein loaded in each line was assessed by stripping and reprobing with a $\beta$-actin antibody.

A

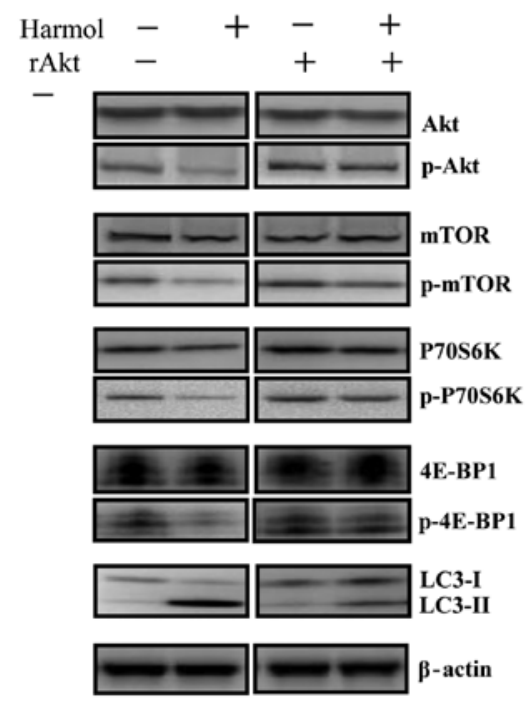

B

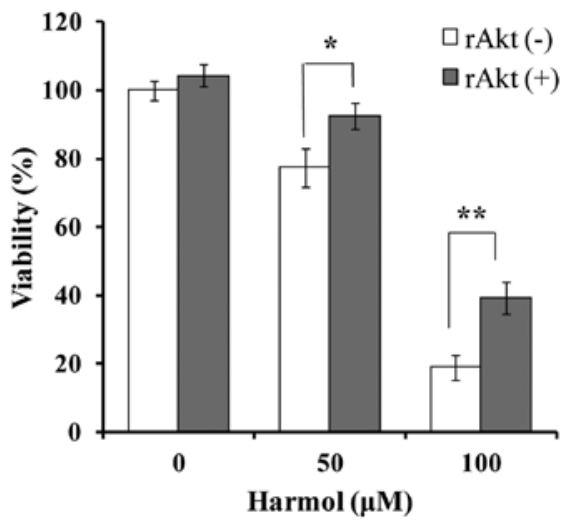

Figure 11. Activation of the Akt pathway by rAkt treatment suppresses harmol-induced autophagy and cytotoxicity in U251MG cells. (A) Western blot analysis of the Akt/mTOR/p70S6K pathway. U251MG cells were treated with $100 \mu \mathrm{M}$ harmol, $500 \mathrm{ng} / \mathrm{ml} \mathrm{rAkt1}$, or both, for $12 \mathrm{~h}$ and subjected to western blotting. (B) Cytotoxic effect was measured using the CellTiter-Blue reagent assay. Cells were treated with different concentrations of harmol, $500 \mathrm{ng} / \mathrm{ml} \mathrm{rAkt1}$, or both, for $48 \mathrm{~h}$. After treatment, cell viability was measured by the CellTiter-Blue assay reagent as described in Materials and methods, and then calculated as a percentage of viability of the control cells. Each value is expressed as mean $\pm \mathrm{SD}$. ${ }^{*} \mathrm{P}<0.05$ and ${ }^{* *} \mathrm{P}<0.001$ indicate a significant difference between the harmol-treated cells and the rAkt plus harmol-treated cells.

examination of the phosphorylation of 2 downstream effectors of mTOR signaling, P70S6K and 4E-BP1, showed that both p-P70S6K and p-4E-BP1 decreased in a time-dependent manner, revealing a potent inhibitory effect of harmol treatment on the Akt/mTOR signaling pathway.

\section{Activation of the Akt pathway inhibits harmol-induced} autophagy and cytotoxicity in U251MG cells. It has been reported that the Akt/mTOR pathway mediates autophagy induced by various anticancer therapies and natural products (35-37). Thus, we used rAkt1 to activate the Akt pathway as described previously (38). In Akt pathway-activated U251MG cells treated with rAkt1, we examined the effect on harmol-induced autophagy and cell death. U251MG cells were treated with $100 \mu \mathrm{M}$ harmol, $500 \mathrm{ng} / \mathrm{ml} \mathrm{rAkt1}$, or both, for $12 \mathrm{~h}$ for western blotting. The addition of rAkt1 inhibited the harmol-induced decrease in phosphorylated Akt, mTOR and P70S6K in U251MG cells (Fig. 11A). Furthermore, the addition of rAkt1 significantly decreased harmol-induced autophagy, confirmed by LC3-II protein expression (Fig. 11A). In the cytotoxicity experiment, the addition of rAkt1 significantly suppressed harmol-induced cytotoxicity in U251MG cells (Fig. 11B).

\section{Discussion}

Previous studies have demonstrated that harmol induced apoptosis in human lung H596 cells through the caspase8-dependent pathway, but independently of Fas/Fas ligand interaction (27). Furthermore, harmol induced autophagic cell death in human lung A549 cells (28). In the present study, we found that harmol induced autophagy and apoptotic cell death in $\mathrm{U} 251 \mathrm{MG}$ cells.

Defects in the regulation of apoptosis are common phenomena in many types of cancer and are also the critical steps in tumorigenesis and resistance to therapy (39). There are two key signaling mechanisms through which cells may be triggered to undergo apoptosis. In the intrinsic 
pathway, diverse stimuli, such as reactive oxygen species, DNA-damaging reagents, and $\mathrm{Ca}^{2+}$ mobilizing agents provoke cell stress or damage, typically by activating one or more members of the $\mathrm{BH} 3$-only protein family, leading to the release of cytochrome $c$. Cytochrome $c$ then binds to apoptosis-activating factor 1 (Apaf-1) and procaspase-9, resulting in the activation of caspase- 9 by proteolytic cleavage. The extrinsic pathway starts with death receptor ligation or Fas/Fas ligand interaction, followed by oligomerization of the receptor, use of Fas-associated death domain (FADD) protein, and activation of caspase-8 (40). Caspase- 8 and -9 have been generally defined as initiator caspases, and can in turn activate caspase-3, the executor of apoptosis $(41,42)$. As shown in Fig. 3, over $36 \mathrm{~h}$ of treatment with harmol increased the activity of both caspase- 9 and -3 , and induced PARP cleavage. However, no noticeable change in the activity of caspase- 8 was observed. From these results, it is assumed that harmolinduced apoptosis was associated with an intrinsic pathway instead of an extrinsic pathway, such as Fas/Fas ligand interaction or the TNF receptor pathway. Although the reasons for the differences in the responses to harmol treatment in $\mathrm{U} 251 \mathrm{MG}$, H596 and A549 cells are unclear, these phenomena in each of these cells might be based on the characteristics of each cell line and the involved stimuli.

Survivin is the smallest member of the inhibitor of apoptosis protein (IAP) family that is selectively overexpressed in most common types of human cancers, but not in normal adult tissues, and has been implicated in the control of cell division, inhibition of apoptosis, and tumor cell resistance to certain anticancer agents and ionizing radiation (43-48). Therefore, these findings make survivin an attractive anticancer drug target. In U251MG cells, we found that harmol suppressed the expression of survivin protein and induced apoptosis associated with activation of caspases and cleavage of PARP, consistent with the role of survivin in antagonizing caspases, thereby blocking apoptosis. Although treatment with harmol alone induced cell death following a 36-h treatment (Fig. 3), the knockdown of survivin expression by specific siRNA sensitized U251MG cells to harmol-induced cell death. Cleaved PARP, a hallmark of apoptosis, was detected within 24 h (Fig. 9B). From these results, the possibility remains that harmol-induced apoptosis is due to the downregulation of survivin protein expression.

Of note, although harmol treatment induced not only apoptosis, but also autophagy (Figs. 5-7), the suppression of survivin protein expression by siRNA also induced autophagy (Fig. 9B, comparing the LC3-II band of the non-treated control sample of control siRNA with the LC3-II band of the non-treated control sample of survivin siRNA). Furthermore, survivin siRNA treatment increased harmol-induced autophagy, as evidenced by conversion of the autophagosomal marker LC3 protein from the cytosolic form (LC3-I) to the membrane-bound, phosphatidylethanolamine-conjugated form (LC3-II), associated with a size shift detected by western blotting (Fig. 9B). In brief, it appears that at first, harmol induces autophagy (induced within $12 \mathrm{~h}$ by treatment with harmol) (Fig. 7) and subsequently reduces the expression of survivin protein. Next, the reduction of survivin protein expression increases autophagy, and finally, apoptosis is induced. Autophagy plays a critical role in the regulation of cell survival or death (12). Therefore, to investigate whether the induction of autophagy by harmol has a cytoprotective function or leads to cell death (i.e., autophagic cell death), we treated U251MG cells with harmol and measured the effects on cell survival or apoptosis in the presence or absence of pharmacological autophagy inhibitors. Although 3-MA treatment significantly reduced harmol-induced cell death, CQ treatment highly enhanced harmol-induced cell death (Fig. 8). In addition, although harmol treatment decreased the expression of survivin, 3-MA treatment in the presence of harmol suppressed the reduction of survivin expression (Fig. 8B). On the other hand, CQ treatment in the presence of harmol did not suppress the reduction of survivin expression (Fig. 8B). The 3-MA molecule, a specific inhibitor of the early-stage autophagic process, is known as a PI3K inhibitor. Class III phosphatidylinositol-3-kinase (class III PI3K) is closely associated with autophagosome membrane formation (10). Therefore, treatment with 3-MA inhibits the formation of autophagic vacuoles. On the other hand, the late-stage autophagy inhibitor CQ blocks the fusion of autophagosomes and lysosomes, thereby suppressing the degradation of the contents within the autophagosome. Considering this information, the possibility remains that when harmol-induced autophagosome formation is inhibited, suppression of survivin protein expression is not induced. In contrast, if an autophagosome is formed, suppression of survivin protein expression occurs, and subsequently apoptosis is induced. In brief, it is assumed that harmol-induced autophagy plays pro-apoptotic roles. However, the detailed mechanisms of these phenomena are unclear. Additional experiments are required to clarify these mechanisms.

Autophagy is regulated by multiple signaling pathways as diverse as class III PI3K (10), protein kinase mTOR $(7,49,50)$, mitogen activated protein kinase (MAPK) $(51,52)$, AMP-activated protein kinase (AMPK) $(53,54)$, Beclin1 (55) and bcl-2 (56). In particular, Akt/mTOR signaling is the major pathway and plays a variety of physiologic roles, including cell growth, cell cycle regulation, migration and survival (57-59). Furthermore, this pathway is also frequently associated with oncogenesis (60). It is known that the Akt/mTOR pathway negatively regulates autophagy (10). Several studies have indicated that inhibition of the Akt/mTOR pathway is associated with the triggering of autophagy in cancer cells (60-63). In U251MG cells, harmol treatment inhibited the phosphorylation of Akt (both Ser473 and Thr308), and moreover, exposure of cells to harmol also inactivated mTOR and reduced phosphorylation of its downstream targets p70S6K and 4E-BP1 (Fig. 10). In contrast, the activation of the Akt pathway by rAkt1 treatment increased the phosphorylation of mTOR and its downstream targets p70S6K and 4E-BP1 (Fig. 11A). Treatment with rAkt1 also improved the viability of harmoltreated U251MG cells (Fig. 11B). These results are consistent with many studies indicating that inhibition of the Akt/mTOR pathway is associated with induction of autophagy in cancer cells $(35,36,50,61)$.

$\beta$-carbolines which occur naturally as harmala alkaloids in Peganum harmala Linné, are also widely found in other medicinal plants $(17,18)$, and are present endogenously in mammalian tissues $(22,23)$. Harmala alkaloids have been used in certain hallucinogenic preparations by some South American and African tribes (62). Furthermore, plants containing harmala alkaloids have long been used in traditional medicine 
to treat asthma, jaundice, lumbago, and other ailments (18-20). Moreover certain $\beta$-carboline alkaloids have a wide spectrum of neuropharmacological and psychopharmacological actions on the central nervous system, such as tremorogenesis $(63,64)$, hypothermia (65), hallucinogenesis $(66,67)$, monoamine oxidase inhibition $(68,69)$, and convulsive or anticonvulsive actions (70). The $\beta$-carboline-induced central nervous effects mainly occur with $\beta$-carbolines which have a methoxyl group at the C-7 position in their structures (71). Therefore, $\beta$-carbolines which have a methoxyl group at the $\mathrm{C}-7$ position are not suitable for chemotherapeutic agents. On the other hand, it is reported that harmol, which has a hydroxyl group at the C-7 position (Fig. 1), showed only slight central depression and convulsive effects (72). Furthermore, harmol has either slight or no tremor-inducing action $(73,74)$.

With regard to its metabolic pathway, harmol is conjugated with sulfate and excreted in the urine and bile; it has a rapid rate of urinary excretion in humans after intravenous administration (75). Therefore, harmol is considered to have low toxicity in humans and animals.

In conclusion, we demonstrated that harmol induces autophagy and apoptosis in U251MG human glioma cells. As these effects of harmol were investigated only in glioma cells, harmol's effects on other types of cancer should also be examined. Furthermore, although additional investigation is needed to precisely clarify the autophagy and apoptosis induction pathway, it is thought to be a candidate pathway that can be targeted by a chemotherapeutic agent in cancer treatment.

\section{Acknowledgements}

We are indebted to Dr Clifford A. Kolba and Associate Professor Edward F. Barroga of the Department of International Medical Communications of Tokyo Medical University for their editorial review of the English manuscript.

\section{References}

1. DeAngelis LM: Brain tumors. N Engl J Med 344: 114-123, 2001

2. Phillips HS, Kharbanda S, Chen R, Forrest WF, Soriano RH, $\mathrm{Wu} \mathrm{TD}$, et al: Molecular subclasses of high-grade glioma predict prognosis, delineate a pattern of disease progression, and resemble stages in neurogenesis. Cancer Cell 9: 157-173, 2006.

3. Kanzawa T, Kondo Y, Ito H, Kondo S and Germano I: Induction of autophagic cell death in malignant glioma cells by arsenic trioxide. Cancer Res 63: 2103-2108, 2003.

4. Fadeel B, Orrenius S and Zhivotovsky B: Apoptosis in human disease: a new skin for the old ceremony? Biochem Biophys Res Commun 266: 699-717, 1999

5. Clarke PG: Developmental cell death: morphological diversity and multiple mechanisms. Anat Embryol 181: 195-213, 1990.

6. Brown JM and Attardi LD: The role of apoptosis in cancer development and treatment response. Nat Rev Cancer 5: 231-237, 2005.

7. Klionsky DJ and Emr SD: Autophagy as a regulated pathway of cellular degradation. Science 290: 1717-1721, 2000.

8. Levine B and Klionsky DJ: Development by self-digestion: molecular mechanisms and biological functions of autophagy. Dev Cell 6: 463-477, 2004.

9. Shintani T and Klionsky DJ: Autophagy in health and disease: a double-edged sword. Science 306: 990-995, 2004.

10. Gozuacik D and Kimchi A: Autophagy as a cell death and tumor suppressor mechanism. Oncogene 23: 2891-2906, 2004.

11. Debnath J, Baehrecke EH and Kroemer G: Does autophagy contribute to cell death? Autophagy 1: 66-74, 2005.

12. Mizushima N, Levine B, Cuervo AM and Klionsky DJ: Autophagy fights disease through cellular self-digestion. Nature 451: 1069-1075, 2008
13. Ogier-Denis E and Codogno P: Autophagy: a barrier or an adaptive response to cancer. Biochim Biophys Acta 1603: 113-128, 2003.

14. Corcelle E, Nebout M, Bekri S, et al: Disruption of autophagy at the maturation step by the carcinogen lindane is associated with the sustained mitogen-activated protein kinase/extracellular signal-regulated kinase activity. Cancer Res 66: 6861-6870, 2006.

15. Otsuka $\mathrm{H}$ and Moscowitz M: Differences in the rates of protein degradation in untransformed and transformed cell lines. Exp Cell Res 112: 127-135, 1978.

16. Kirkegaad K, Taylor MP and Jacson WT: Cellular autophagy: surrender, avoidance and subversion by microorganisms. Nat Rev Microbiol 2: 301-314, 2004.

17. List PH and Hörhammer L: Hager's Hand book for Pharmaceutical Practice. Springer-Verlag, Berlin, 1970.

18. Naranjo C: Psychotropic properties of the harmala alkaloids. In: Ethnopharmacological Search for Psychoactive Drugs. Efron DH, Holmestedt B and Kline NS (eds). U.S. Public Health Service, New York, pp385-392, 1967.

19. Nadikarni KM: Indian Material Medica. Vol. 1. Popular Pakistan Limited, Bombay, pp927-929, 1976.

20. Dymock W, Warden CJ and Hooper D: Pharmacopia Indica. Vol. 1. Harmad National Foundation of Pakistan, pp252-253, 1976.

21. Khan SI, Abourashed EA, Khan IA and Walker LA: Transport of human alkaloids across Caco-2 cell monolayers. Chem Pharm Bull 52: 394-397, 2004.

22. Airaksinen MM and Kari I: $\beta$-carbolines, psychoactive compounds in the mammalian body. Part I: occurrence, origin and metabolism. Med Biol 59: 21-34, 1981.

23. Beck O and Faull KF: Concentrations of the enantiomers of 5-hydroxymethylptoline in mammalian urine: Implications for in vivo biosynthesis. Biochem Pharmacol 65: 97-106, 1986.

24. Sobhani AM, Ebrahimi SA and Mahmoudian MJ: An in vitro evaluation of human DNA topoisomerase I inhibition by Peganum harmala L. seed extract and its beta-carboline alkaloids. Pharm Pharm Sci 5: 19-23, 2002.

25. Lamchouri F, Setaff A, Cherrah Y, et al: Antitumor principles from Peganum harmala seeds. Therapie 54: 753-758, 1999.

26. Kuo PC, Shi LS, Damu AG, et al: Cytotoxic and antimalarial beta-carboline alkaloids from the roots of Eurycoma longifolia. J Nat Prod 66: 1324-1327, 2003.

27. Abe A and Yamada H: Harmol induces apoptosis by caspase- 8 activation independently of Fas/Fas ligand interaction in human lung carcinoma H596 cells. Anticancer Drugs 20: 373-381, 2009.

28. Abe A, Yamada H, Moriya S and Miyazawa K: The $\beta$-carboline alkaloid harmol induces cell death via autophagy but not apoptosis in human non-small cell lung cancer A549 cells. Biol Pharm Bull 34: 1264-1272, 2011.

29. Oliver FJ, de la Rubia G, Rolli V, Ruiz-Ruiz MC, de Murcia G and Murcia JM: Importance of poly(ADP-ribose) polymerase and its cleavage in apoptosis. Lesson from an uncleavable mutant. J Biol Chem 273: 33533-33539, 1998.

30. Biederbick A, Kern HF and Elsässer HP: Monodansylcadaverine (MDC) is a specific in vivo marker for autophagic vacuoles. Eur J Cell Biol 66: 3-14, 1995.

31. Kabeya Y, Mizusima N, Ueno T, et al: LC3, a mammalian homologue of yeast Apg8p, is localized in autophagosome membranes after processing. EMBO J 19: 5720-5728, 2000.

32. Seglen PO and Gordon PB: 3-Methyladenine: specific inhibitor of autophagic/lysosomal protein degradation in isolated rat hepatocytes. Proc Natl Acad Sci USA 79: 1889-1892, 1982.

33. Kawai A, Uchiyama $H$, Takano $S$, Nakamura $S$ and Ohkuma $S$ : Autophagosome-lysosome fusion depends on the $\mathrm{pH}$ in acidic compartments in CHO cells. Autophagy 3: 154-157, 2007.

34. Rubinsztein DC, Gestwicki JE, Murphy LO and Klionsky DJ: Potential therapeutic applications of autophagy. Nat Rev Drug Discov 6: 304-312, 2007.

35. Fu L, Kim AY, Wang X, et al: Perifosine inhibits mammalian target of rapamycin signaling through facilitating degradation of major components in the mTOR axis and induces autophagy. Cancer Res 69: 8967-8976, 2009.

36. Viola G, Bortolozzi R, Hamel E, et al: MG-2477, a new tubulin inhibitor, induces autophagy through inhibition of the Akt/ mTOR pathway and delayed apoptosis in A549 cells. Biochem Pharmacol 8: 16-26, 2012.

37. Hung JY, Hsu YL, Li CT, et al: 6-Shogaol, an active constituent of dietary ginger, induces autophagy by inhibiting the AKT/ mTOR pathway in human non-small cell lung cancer A549 cells. J Agric Food Chem 57: 9809-9816, 2009. 
38. Takeuchi H, Kanzawa T, Kondo Y and Kondo S: Inhibition of platelet-derived growth factor signaling induces autophagy in malignant glioma cells. Br J Cancer 90: 1069-1075, 2004.

39. Hanahan D and Weinberg RA: The hallmarks of cancer. Cell 100: 57-70, 2000.

40. Gross A, Yin XM, Wang K, et al: Caspase cleaved BID targets mitochondria and is required for cytochrome c release, while BCL-XL prevents this release but not tumor necrosis factor-R1/ Fas death. J Biol Chem 274: 1156-1163, 1999.

41. Zha J, Weiler S, Oh KJ, Wei MC and Korsmeyer SJ: Posttranslational N-myristoylation of BID as a molecular switch for targeting mitochondria and apoptosis. Science 290: 1761-1765, 2000.

42. Shao RG, Cao CX, Nieves-Neira W, Dimanche-Boitrel MT, Solary E and Pommier Y: Activation of the Fas pathway independently of Fas ligand during apoptosis induced by camptothecin in p53 mutant human colon carcinoma cells. Oncogene 20 $1852-1859,2001$.

43. Deveraux Q and Reed JC: IAP family proteins: suppressors of apoptosis. Genes Dev 13: 239-252, 1999.

44. Li F, Ambrosini G, Chu EY, et al: Control of apoptosis and mitotic spindle checkpoint by survivin. Nature 396: 580-584, 1998.

45. Monzo M, Rosell R, Felip E, et al: A novel anti-apoptosis gene: re-expression of surviving messenger RNA as a prognosis marker in non-small-cell lung cancers. J Clin Oncol 17: 2100-2104, 1999.

46. Adida C, Haioun C, Gaulard P, et al: Prognostic significance of surviving expression in diffuse large B-cell lymphomas. Blood 96: 1921-1925, 2000.

47. Kato J, Kuwabara Y, Mitani M, et al: Expression of surviving in esophageal cancer: correlation with the prognosis and response to chemotherapy. Int J Cancer 95: 92-95, 2001.

48. Altieli DC: Survivin, cancer networks and pathway-directed drug discovery. Nat Rev Cancer 8: 61-70, 2008.

49. Levine B and Yuan J: Autophagy in cell death: an innocent convict? J Clin Invest 115: 2679-2688, 2005.

50. Guertin DA and Sabatini DM: Defining the role of mTOR in cancer. Cancer Cell 12: 9-22, 2007.

51. Petiot A, Pattingre S, Arico S, Meley D and Codongo P: Diversity of signaling controls of macroautophagy in mammalian cells. Cell Struct Funct 27: 431-441, 2002.

52. Pattingre $\mathrm{S}$, Bauvy $\mathrm{C}$ and Codongo $\mathrm{P}$ : Amino acids interfere with the ERK1/2-dependent control of macroautophagy by controlling the activation of Raf-1 in human colon cancer HT-29 cells. J Biol Chem 278: 16667-16674, 2003.

53. Meley D, Bauvy C, Houben-Weerts JH, et al: AMP-activated protein kinase and the regulation of autophagic proteolysis. J Biol Chem 281: 34870-34879, 2006.

54. Herrero-Martín G, Høyer-Hansen M, García-García C, et al: TAK1 activates AMPK-dependent cytoprotective autophagy in TRAIL-treated epithelial cells. EMBO J 28: 677-685, 2009.

55. Djavaheri-Mergny M, Maiuri MC and Kroemer G: Cross talk between apoptosis and autophagy by caspase-mediated cleavage of Beclin 1. Oncogene 29: 1717-1719, 2010.

56. Zhou F, Yang Y and Xing D: Bcl-2 and Bcl-xL play important roles in the crosstalk between autophagy and apoptosis. FEBS J 278: 403-413, 2011.

57. Lin CC, Lee CW, Chu TH, et al: Transactivation of Src, PDGF receptor, and Akt is involved in IL-1beta-induced ICAM-1 expression in A549 cells. J Cell Physiol 211: 771-780, 2007.
58. Russo P, Catassi A, Cesario A and Servent D: Development of novel therapeutic strategies for lung cancer: targeting the cholinergic system. Curr Med Chem 13: 3493-3512, 2006.

59. Akca H, Tani M, Hishida T, Matsumoto S and Yokota J: Activation of the AKT and STAT3 pathways and prolonged survival by a mutant EGFR in human lung cancer cells. Lung Cancer 54: 25-33, 2006.

60. Kishimoto H, Ohteki T, Yajima N, et al: The Pten/PI3K pathway governs the homeostasis of Valpha14iNKT cells. Blood 109: 3316-3324, 2007.

61. Takeuchi H, Kondo Y, Fujiwara K, et al: Synergistic augmentation of rapamycin-induced autophagy in malignant glioma cells by phosphatidylinositol 3-kinase/protein kinase B inhibitors. Cancer Res 65: 3336-3346, 2005.

62. Rommelspacher H, Nanz C, Borbe HO, Fehske KJ, Müller WE and Wollert U: 1-Methyl-beta-carboline (harmane), a potent endogenous inhibitor of benzodiazepine receptor binding. Naunyn Schmiedebergs Arch Pharmacol 314: 97-100, 1980.

63. Ho BT: Pharmacological and biochemical studies with betacarboline analogs. Curr Dev Psychopharmacol 4: 151-177, 1977.

64. Poirier LJ, Sourkes TL, Bouvier G, Boucher R and Carabin S: Striatal amines, experimental tremor and the effect of harmaline in the monkey. Brain 89: 37-52, 1966.

65. Bruinvels J and Sourkes TL: Influence of drugs on the temperature-lowering effect of harmaline. Eur J Pharmacol 4: 31-39, 1969

66. Zetler G, Back G and Iven H: Pharmacokinetics in the rat of the hallucinogenic alkaloids harmine and harmaline. Naunyn Shemiedebergs Arch Pharmacol 285: 273-292, 1974.

67. Grella B, Dukat M, Young R, et al: Investigation of hallucinogenic and related beta-carbolines. Drug Alcohol Depend 50: 99-107, 1998.

68. Udenfriend S, Wiycop B, Redfield BG and Weissbach H: Studies with reversible inhibitors of monoamine oxidase: harmaline and related compounds. Biochem Pharmacol 1: 160-165, 1958.

69. McIsaac WM and Estevez V: Structure-action relationship of beta-carbolines as monoamine oxidase inhibitors. Biochem Pharmacol 15: 1625-1627, 1966.

70. Loew GH, Nienow J, Lawson JA, Toll L and Uyeno ET: Theoretical structure-activity studies of beta-carboline analogs. Requirements for benzodiazepine receptor affinity and antagonist activity. Mol Pharmacol 28: 17-31, 1985.

71. Kim H, Sablin SO and Ramsay RR: Inhibition of monoamine oxidase A by $\beta$-carboline derivatives. Arch Biochem Biophys 337: 137-142, 1997

72. Gunn JA: Relations between chemical constitution, pharmacological actions, and therapeutic uses in the harmine group of alkaloids. Arch Int Pharmacodyn 50: 379-396, 1935.

73. Zetler G, Singbart G and Schlosser L: Cerebral pharmacokinetics of tremor-producing harmala and iboga alkaloids. Pharmacology 7: 237-248, 1972

74. Yu AM, Idle JR, Krausz KW, Küpfer A and Gonzalez FJ. Contribution of individual cytochrome P450 isozymes to the $\mathrm{O}$-demethylation of the psychotropic beta-carboline alkaloids harmaline and harmine. J Pharmacol Exp Ther 305: 315-322, 2003.

75. Slotkin TA, DiStefano V and Au WY: Blood levels and urinary excretion of harmine and its metabolites in man and rats. J Pharmacol Exp Ther 173: 26-30, 1970. 